\title{
Reliability-Based Design Optimization of Pump Penetration Shell Accounting for Material and Geometric Non-Linearity
}

\author{
Gautham Velayudhan* - Prabhu Raja Venugopal - Ebron Shaji Gnanasigamony Thankareathenam - Mohanraj \\ Selvakumar - Thyla Pudukarai Ramaswamy \\ PSG College of Technology, Department of Mechanical Engineering, India
}

The roof slab of a nuclear reactor supports all the components and sub-systems. It needs to resist the seismic loads in accordance with load-carrying criteria. The static stress analysis of the reactor roof slab reveals that high-stress concentration was present in the pump penetration shell (PPS) that supports the primary sodium pump. This paper presents an assessment of collapse load and the optimization of the pump penetration shell through the reliability approach, accounting for material non-linearity, geometrical non-linearity and randomness in loading. In addition, the load-carrying capacity of PPS was determined considering two different materials: IS2062 and A48P2. The design of experiments $(\mathrm{DoE})$ was formulated considering the flange angle and flange thickness as parameters. An empirical model for load function was formulated from the results of the collapse load obtained for various combinations of design parameters. The above function was used to perform the reliability-based geometry optimization of the PPS of the roof slab.

Keywords: nuclear reactor; buckling; optimization; reliability; limit load; genetic algorithm

Highlights

- $\quad$ The reliability-based design of the pump penetration shell is adapted to account for material properties that are uncertain.

- The methodology of incorporating the reliability index for reliability-based design has been studied, and a genetic algorithm optimization technique is adopted for performing design optimization of the pump penetration shell.

- The prediction of collapse load of a single-layer PPS reveals that the PPS made of IS2062 has a higher load-carrying capacity than the PPS made of A48P2.

- $\quad$ The PPS made of IS2062 has less influence of effect of mode shapes and imperfection on the collapse load compared with the PPS made of material A48P2.

- $\quad$ The load-carrying capacity of the PPS increasing with the increase of angle and thickness of the flange.

\section{INTRODUCTION}

Considering the geometrical configuration of the roof slab of a nuclear reactor, a large box-type structure with many penetrations made of carbon steel, posed many difficulties during manufacturing, particularly due to lamellar tearing. Alternatively, taking advantage of high-load carrying capacity with possibly minimum thickness, a dome-shaped roof slab was conceived comprised of a conical shell connected to the vertical shell through a short torus portion [1].

The structural integrity of the roof slab is significant for the safe and reliable functioning of the reactor [2]. Structural integrity refers to the condition of a structural system and implies that the structure and its components remain intact over the intended lifetime of the structure. The roof slab is subjected to fatigue loading due to the reaction taking place inside the main vessel and the intermittent flow of sodium [1]. The fatigue phenomenon is a complex and progressive failure; one possibility of occurrence could be from a small weld defect. The failure begins with the formation of micro-cracks and crack propagation, leading to the failure of the structure.
Reliability is an aspect of engineering uncertainty. It is the probability that an item will perform a required function without failure under stated conditions for the stated period [3] to [7]. Durability is a particular aspect of reliability related to the ability of an item to withstand the effects of time or operating cycles, etc. The main objective of any structural design is to ensure the safety and economy of the structure operating under a given environment. Hence, the demand should not exceed the capacity of the structure.

$$
\text { Capacity }(C)>\text { Demand }(D)
$$

The above-cited condition should be satisfied so that the structure's safety is ensured for the intended purpose for which the structure is built. The deterministic approach is based on the premise that a given problem can be stated in the form of a question or a set of questions to which there is an explicit and distinct answer. A probabilistic approach is based on the concept that several or varied outcomes of a situation are possible to this approach in which uncertainty is recognized. Probabilistic modelling aims at the study of a range of outcomes for the given set of input data. Accordingly, the description of a 
physical situation or system includes the randomness of data and other kinds of uncertainties.

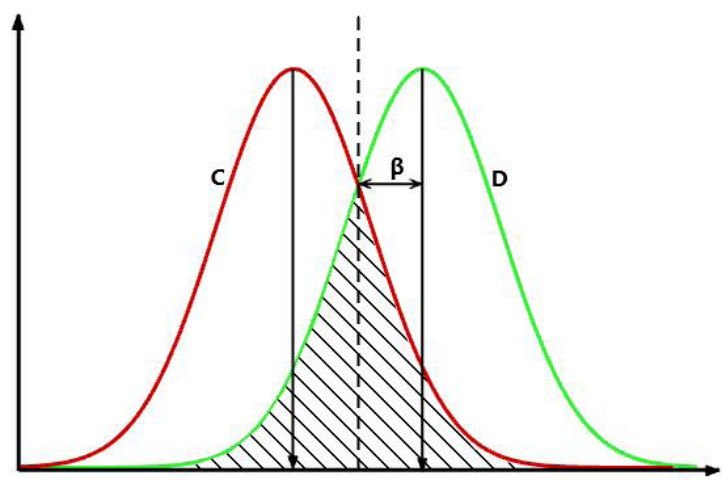

Fig. 1. Probabilistic approach

The probability of failure is the common area shared by both the demand and capacity curves as shown in Fig. 1. The reason for this is that $C$ is always less than $D$ in the shaded area, hence ensuring failure. Considering the probability density function for the normal distribution of capacity and demand curve, the measure of reliability is defined with a term known as the reliability index $(\beta)$, as shown in Fig. 1 , as proposed by Cornell et al. [8]. It is the shortest distance measured from the origin when the capacity and demand are expressed. The random variables are characterized by their first two moments only, i.e., mean and variance. This is achieved by first-order approximation of the non-linear function; therefore, this method is termed a first-order second moment (FOSM) method.

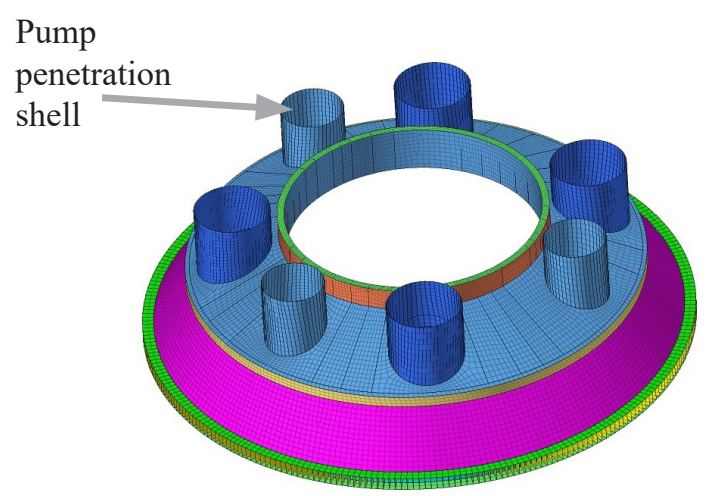

Fig. 2. Dome shaped roof slab model

The pump penetration shell is one of the critical components of the dome-shaped roof slab (Fig. 2). Hence, it is essential to analyse the load-carrying capacity of the roof slab to ensure structural integrity. The primary objective of the work is to perform reliability-based design optimization of the pump penetration shell (PPS) using a genetic algorithm and compare the load-bearing capacity of PPS made of materials IS2062 and A48P2. It is essential to optimize the design parameters of the PPS for maximum loadcarrying capacity with a reduced volume of PPS. Prior to performing the non-linear analysis of the roof slab, a benchmarking study that involves the prediction of collapse load of a simpler structure is carried out.

\section{BENCHMARK STUDY ON PREDICTION OF COLLAPSE LOAD FOR SIMPLE STRUCTURE}

In order to ascertain the methodology to be adopted for performing the non-linear analysis of roof slab, a simpler problem proven experimentally by Zhou et al. [9] is taken up for benchmark study. The problem involves the determination of the limit load of the steel pyramid-to-tube socket connection subjected to uniform compression. Ansys Workbench finite element software is used. The geometric and meshed models of the steel structure are shown in Figs. 3 and 4 , respectively. The material properties of the structure are given in Table 1.

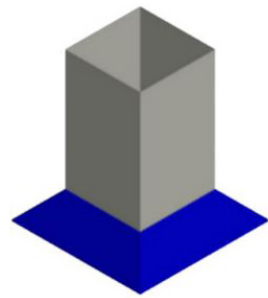

Fig. 3. Geometric model of structure

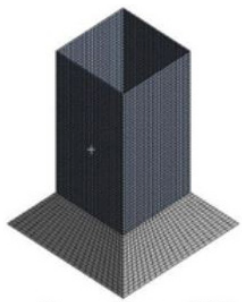

Fig. 4. Meshed model of structure
Table 1. Material properties of the structure [9]

\begin{tabular}{lcc}
\hline Component & Tube Socket & Steel Pyramid \\
\hline Steel type & STKR400 & SS400 \\
\hline Measured plate thickness [mm] & 4.2 & 4.2 \\
\hline Young's modulus [N/mm²] & 207893 & 204076 \\
\hline Yield strength [N/mm²] & 378 & 348 \\
\hline Ultimate strength [N/mm²] & 454 & 433 \\
\hline Uniform elongation [\%] & 17 & 17 \\
\hline
\end{tabular}

Initially, the critical load was predicted by performing linear buckling analysis by fixing the bottom end of the pyramid and applying a uniform compressive load at the top, without considering the non-linear behaviour of the structure [10] to [13]. The critical buckling load of the structure is found to be $1867 \mathrm{kN}$ and the corresponding displacement contour is shown in Fig. 5. 


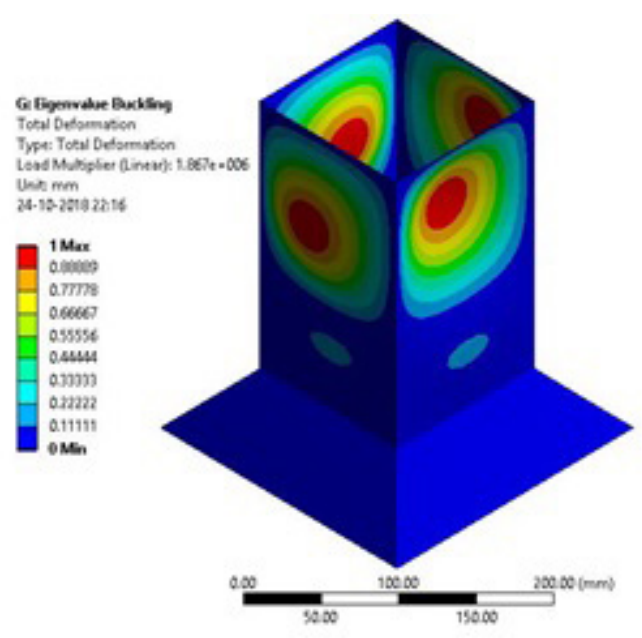

Fig. 5. Buckling mode of steel structure (Mode 1)

Table 2. Comparison of numerical and benchmark results

\begin{tabular}{lccc}
\hline Description & $\begin{array}{c}\text { Numerical } \\
\text { result }\end{array}$ & $\begin{array}{c}\text { Benchmark } \\
\text { result [9] }\end{array}$ & $\begin{array}{c}\text { Deviation } \\
{[\%]}\end{array}$ \\
\hline Buckling load [kN] & 1867 & 1910 & 2.24 \\
\hline
\end{tabular}

The results obtained from numerical analysis are found to be in close agreement with experimental results by Zhou et al. [9], as shown in Table 2. Hence, the above methodology can be extended for the numerical prediction of the collapse load of the PPS.

Since the present work deals with optimizing the pump penetration shell for higher load-carrying capacity, a benchmark study that involves the application of reliability approach and genetic algorithm is carried out prior to performing the reliability-based design optimization of the reactor roof slab.

\section{A BENCHMARK STUDY OF RELIABILITY-BASED DESIGN OPTIMIZATION}

A cantilever beam subjected to bending loads is considered for performing reliability-based design optimization. In general, design parameters, such as material properties and geometrical dimensions, as well as boundary and loading conditions, are prefixed while designing any structure. However, in the case of reliability-based design optimization, the limit state function that relates the capacity $(R)$ and demand $(S)$ of the function should be derived as a function ' $g$ ' of the variables. When $g$ is greater than zero, then the structure is considered to be a safe structure. The limit state function is given by:

$$
g=R-S .
$$

In reliability-based design, the limit state function $g$ is a random variable because of the uncertainties involved in load and yield strength. The reliability index $\beta$ is a direct measure of the reliability of the system and hence a larger value of $\beta$ represents higher reliability. For structural applications, the reliability index is generally taken as 3 , for which the probability of failure is 0.00135 [14].

A cantilever beam shown in Fig. 6 is taken up for benchmark study for which Wang et al. [15] have prescribed the results of the reliability-based design optimization. The width, height, and thickness of the beam of a length $(l)$ of $3048 \mathrm{~mm}$, are designated as $w, h$ and $t$, respectively. The loads acting at the free end of the cantilever beam, along $x$ and $y$-axes are designated as $P_{x}$ and $P_{y}$, respectively. The moments of inertia of the cantilever beam about $x$-axis and $y$-axis are represented as $I_{x x}$ and $I_{y y}$ respectively. In the limit state function, $R$ and $S$ represent the yield strength of material and the maximum bending stress, respectively.

The mean and standard deviation of the load acting in $x$-axis are $2224 \mathrm{~N}\left(P_{x}\right)$ and $667 \mathrm{~N}\left(s_{x}\right)$ (respectively while the corresponding values for load acting in y-axis are $4448 \mathrm{~N}\left(P_{y}\right)$ and $222 \mathrm{~N}\left(s_{y}\right)$. The mean and standard deviations of the material yield strength are $276 \mathrm{MPa}(R)$ and $14 \mathrm{MPa}\left(s_{R}\right)$, respectively. The objective is to design the cantilever beam for a minimum weight with the given constraints:

$$
\begin{gathered}
\beta>3 ; 50 \mathrm{~mm} \leq w, h \leq 254 \mathrm{~mm} ; \\
2.5 \mathrm{~mm} \leq t \leq 13 \mathrm{~mm} .
\end{gathered}
$$

Since the system involves more than two random variables, the FOSM method is used to obtain the
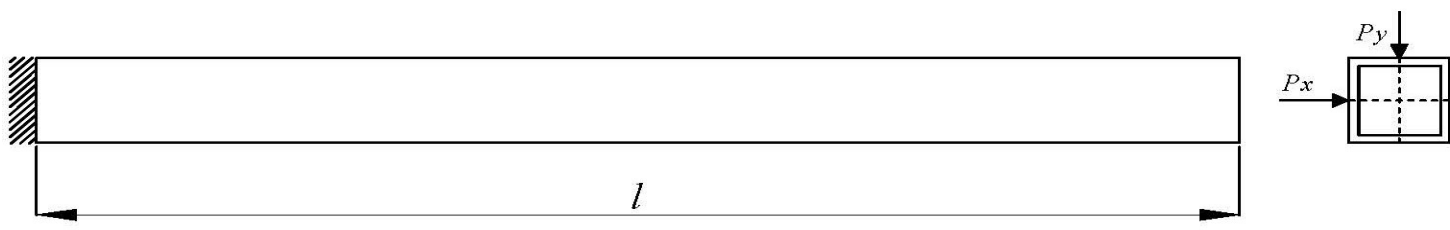

Fig. 6. Loads acting on the cantilever beam 
mean $\left(\mu_{g}\right)$ and standard deviation $\left(\sigma_{g}\right)$ of the limit state function.

$$
\begin{gathered}
g=r-\left(\frac{l w P_{x}}{2 I_{y y}}+\frac{l h P_{y}}{2 I_{x x}}\right), \\
\sigma_{g}^{2}=\left[\left(\frac{\partial g}{\partial R}\right)^{2} S_{R}^{2}\right]+\left[\left(\frac{\partial g}{\partial P_{x}}\right)^{2} S_{x}^{2}\right]+\left[\left(\frac{\partial g}{\partial P_{y}}\right)^{2} S_{y}^{2}\right], \\
\frac{\partial g}{\partial R}=1, \\
\frac{\partial g}{\partial P_{x}}=\frac{l w}{2 I_{y y}}, \\
\sigma_{g}=\sqrt{\left[\left(\frac{\partial g}{\partial R}\right)^{2} S_{R}^{2}\right]+\left[\left(\frac{\partial g}{2 I_{x x}}\right)^{2} S_{x}^{2}\right]+\left[\left(\frac{\partial g}{\partial P_{y}}\right)^{2} S_{y}^{2}\right]}, \\
\beta=\frac{\mu_{g}}{\sigma_{g}} .
\end{gathered}
$$

The above equations are incorporated into the MATLAB optimization tool, and the objective function is minimized using a genetic algorithm [16] to [18]. The optimization results are compared with that of Wang et al. [15] and are shown in Table 3.

Table 3. Comparison of results based on reliability-based optimization

\begin{tabular}{lcccc}
\hline & $\begin{array}{c}\text { Area [mm2] } \\
\text { (objective } \\
\text { function) }\end{array}$ & $\begin{array}{c}t \\
{[\mathrm{~mm}]}\end{array}$ & $\begin{array}{c}w \\
{[\mathrm{~mm}]}\end{array}$ & $\begin{array}{c}h \\
{[\mathrm{~mm}]}\end{array}$ \\
\hline $\begin{array}{l}\text { Based on } \\
\text { genetic algorithm }\end{array}$ & 1770 & 2.54 & 169 & 184 \\
\hline $\begin{array}{l}\text { Results by } \\
\text { Wang et al. [15] }\end{array}$ & 1772 & 2.54 & 179 & 175 \\
\hline
\end{tabular}

It is inferred from the above table that the results obtained from that predicted by Wang et al. [15] are in good agreement. Hence, the validated methodology for reliability-based optimization is extended for the pump penetration shell, which is described in the next section.

\section{RELIABILITY-BASED DESIGN OPTIMIZATION OF PUMP PENETRATION SHELL}

In order to ensure the reliability of the PPS, the variability in the flange thickness and flange angle must be considered during structural design. The objective is to minimize the weight of the PPS, which is achieved by minimizing the volume of the structure. The volume of the PPS is given by the sum of the volumes of the cylindrical part and the conical part. $V_{1}$ and $V_{2}$ are the volumes of the hollow cylinder and truncated hollow cone, respectively. $R_{1}$ and $R_{2}$ are the outer and inner radii of the bottom surface of the cone, $r_{1}$ and $r_{2}$ are the outer and inner radii of the cylinder, $h_{y}$ and $h_{c}$ are the heights of the cylinder and the cone respectively.

where, $r_{2}=88 ; r_{1}=r_{2}+t$,

$$
V_{1}=\left(\pi h_{y}\right)\left[r_{1}^{2}-r_{2}^{2}\right],
$$

$$
V_{2}=\left(\frac{\pi h_{c}}{3}\right)\left[\left(R_{1}^{2}+R_{1} r_{1}+r_{1}^{2}\right)-\left(R_{2}^{2}+R_{2} r_{2}+r_{2}^{2}\right)\right],
$$

where, $R_{2}=128 ; R_{1}=R_{2}+t$,

$$
V=V_{1}+V_{2} \text {. }
$$

The constraints imposed on the PPS for reliability-based design are given as follows, $\beta>3$; $0^{\circ} \leq \theta \leq 30^{\circ} ; 1 \mathrm{~mm} \leq t \leq 3 \mathrm{~mm}$.

For the limit state function ( $g$ function) given in Eq. (1), $R$ and $S$ represent collapse load and applied load or operating load $(10 \mathrm{kN})$, respectively. The calculation of collapse load for PPS is discussed in later sections.

\subsection{Determination of Collapse Load for PPS}

The elasto-plastic analysis of PPS is carried out considering two different materials, namely IS2062 and A48P2, which are commonly used in the fabrication of the prototypes of the reactor roof slab. The collapse load behaviour of the PPS made of IS2062 and A48P2 will be compared in this section. The PPS is idealized as a shell body, and it is scaled down to 1:10 ratio from the actual reactor roof slab to facilitate experimentation. The geometry of PPS shown in Fig. 7 is modelled and meshed with SHELL 181 elements. The mesh convergence study was carried out to idealize the element size. Prior to determining the collapse load, it is necessary to determine the buckling mode, which has a considerable influence on the failure of the structure.

From experimental investigation on static loading, it was observed that buckling occurred in the conical portion of the structure with imperfection. Hence, Modes 2, 9, 16, 23, and 30, which correspond to buckling in the conical portion of the structure are considered for numerical analysis, both for linear buckling analysis and elasto-plastic analysis. The 
mode shapes of PPS made of IS2062 are shown in Fig. 8. Similar mode shapes were also observed for the PPS made of A48P2. Subsequently, elasto-plastic analysis was performed, and the collapse load of PPS was predicted by using the elastic slope method twice [19] and [20].

It is inferred from Fig. 9 that there is no considerable influence of mode shape on the collapse load of PPS made of IS2062. In contrast, the influence of mode shape on the collapse load of PPS made of A48P2 is considerable, as shown in Fig. 10. It is found that the collapse load is the lowest corresponding to

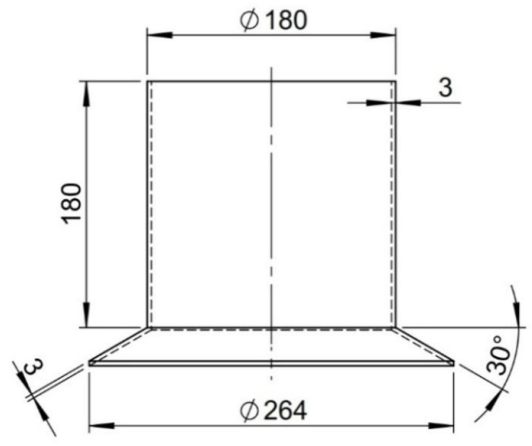

Fig. 7. Geometric model of pump penetration shell

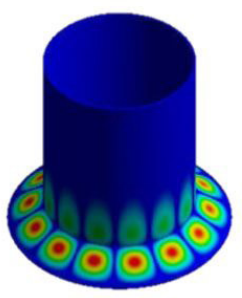

a) Mode 2

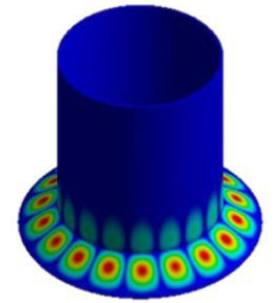

b) Mode 9

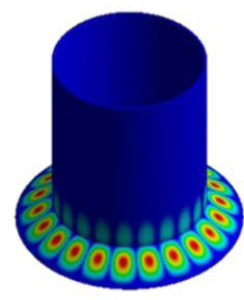

c) Mode 16

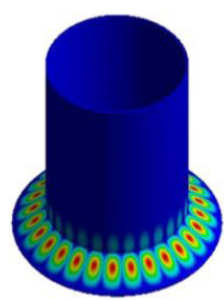

d) Mode 23

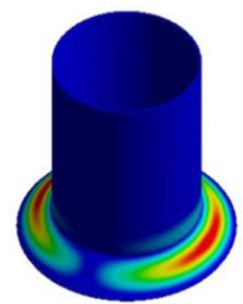

e) Mode 30

Fig. 8. Mode shapes of PPS made of IS2062

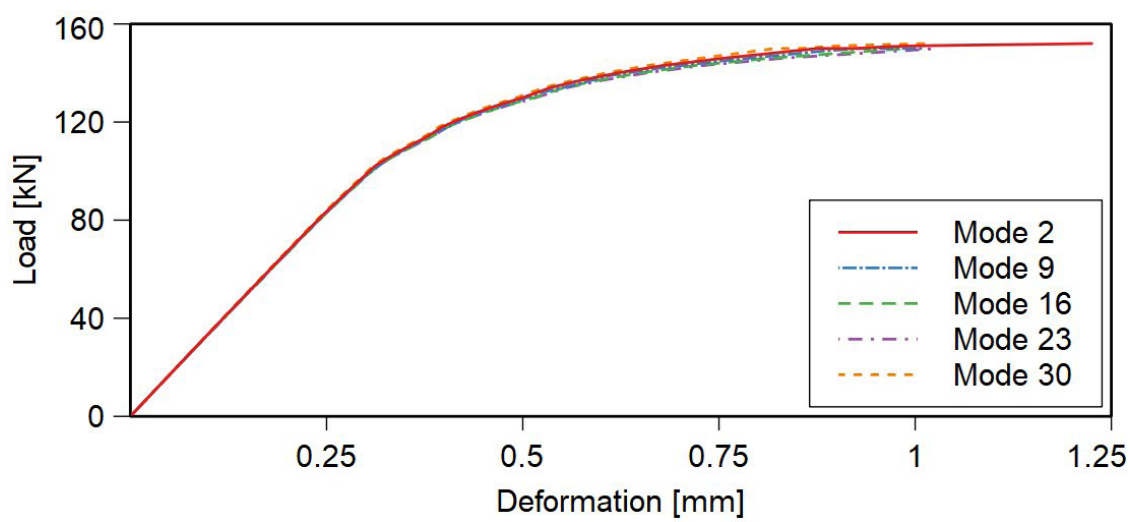

Fig. 9. Effect of mode shape on collapse load of PPS made of IS2062

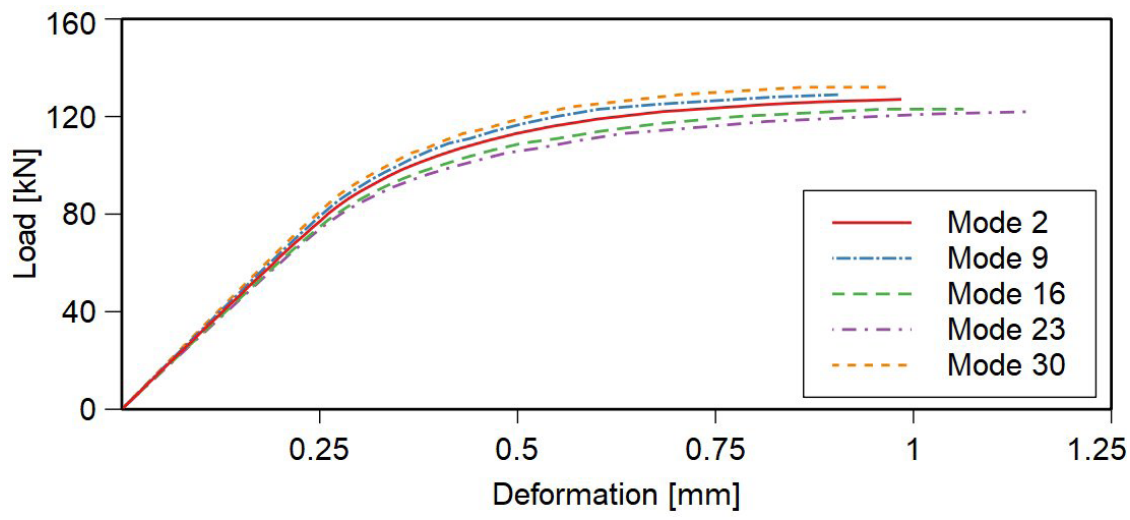

Fig. 10. Effect of mode shape on collapse load of PPS made of A48P2 
Mode 23. It is observed that Mode 23 is characterized by multiple lobes, whereas only two lobes are present in Mode 30. The presence of multiple smaller lobes will offer lower resistance to collapse and vice-versa. Hence, Mode 30 for A48P2 has a higher collapse load than Mode 23. Thus, the above mode is considered for further study on the effect of imperfection on collapse load. The surface irregularities are considered to be imperfections in the PPS. It is found from the analysis that the imperfection below $50 \%$ of shell thickness does not influence the collapse load of the structure. Any imperfections greater than $90 \%$ of shell thickness are not acceptable as per manufacturing standards. Hence, the imperfection levels considered for this analysis are $50 \%, 70 \%$, and $90 \%$ of the thickness of the PPS.

It is inferred from Fig. 11 that there is no significant influence of imperfection on collapse load of PPS made of IS2062. However, the influence of imperfection on the collapse load of PPS made of A48P2 is considerable, as shown in Fig. 12. It is inferred from Fig. 9 to 12 that the influence of mode shape and geometrical imperfection on loaddeformation characteristics with material A48P2 is minimal. In contrast, the above influence is pronounced with material IS2062, which is attributed to the variation in slope in the non-linear zone of the stress-strain curve.

It is also found that the collapse load is the lowest, corresponding to an imperfection level of $90 \%$, and thus the above imperfection level is considered. In order to determine the collapse load for the generated design points, the buckling mode shape (Mode 23) and the geometrical imperfection level of $90 \%$ are considered for further investigation.

\subsection{Experimental Validation of Collapse Load on PPS}

An experimental investigation was done on the pump penetration shell. The PPS prototype model taken for experimentation has the diameters of the cylindrical part and conical skirt as $180 \mathrm{~mm}$ and $264 \mathrm{~mm}$, respectively, with $3 \mathrm{~mm}$ thickness as shown in Fig. 7. The PPS was mounted in the fixture, and load was gradually applied on PPS using UTM until it attained permanent deformation. The geometrical shapes of PPS before and after collapse are shown in Figs. 13 and 14 , respectively.

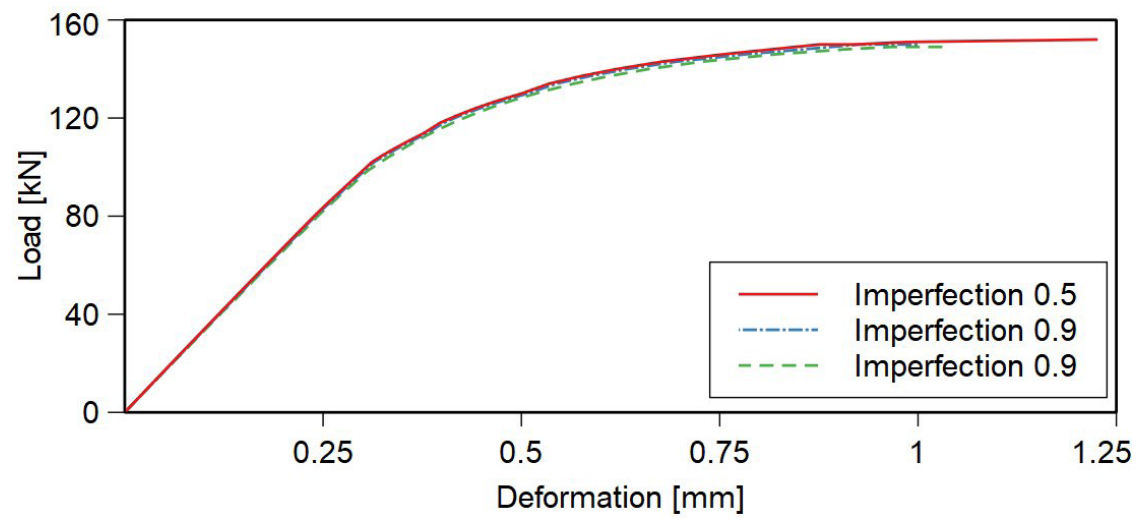

Fig. 11. Effect of imperfection on collapse load of PPS made of IS2062

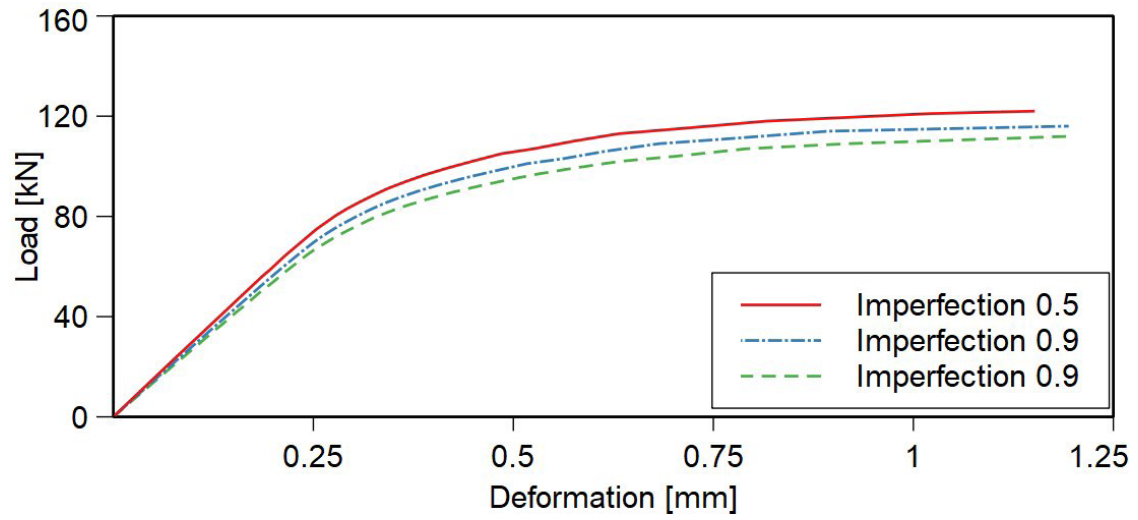

Fig. 12. Effect of imperfection on collapse load of PPS made of A48P2 


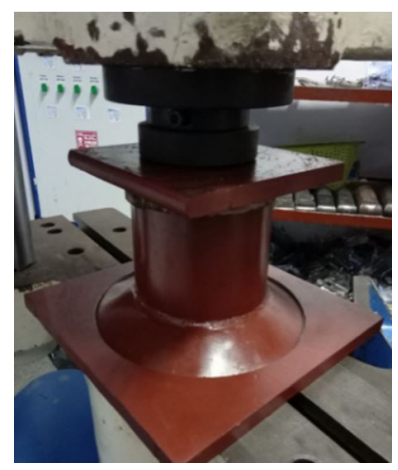

Fig. 13. PPS specimen before collapse

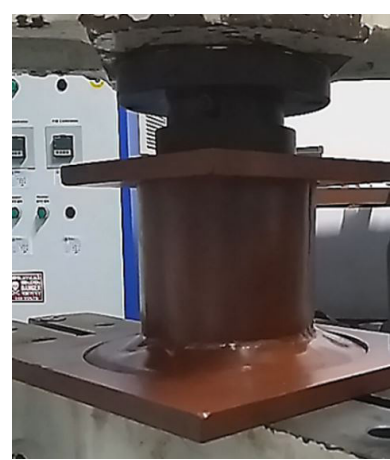

Fig. 14. PPS specimen after collapse

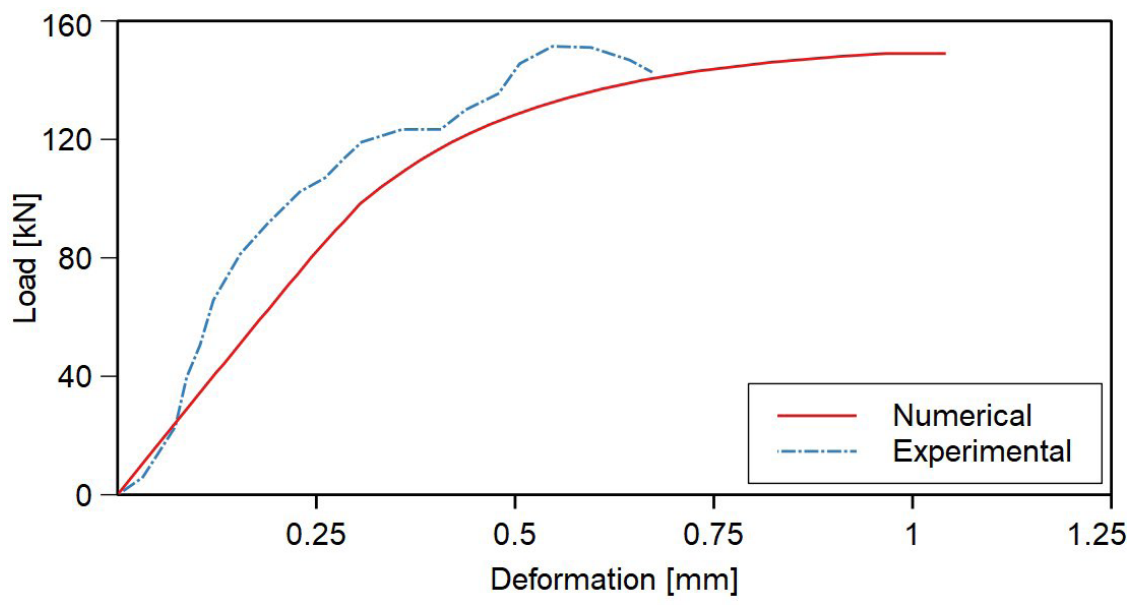

Fig. 15. Comparison of collapse load of PPS specimen

Since, the numerically predicted Mode 23 matches with the experimentally observed mode of collapse in the conical region of the PPS specimen, a comparison of the load-deformation characteristics corresponding to Mode 23 is presented in Fig. 15. Considering the numerically predicted load-displacement curve, the collapse load of the structure is found to be $122 \mathrm{kN}$ by using the twice elastic slope method. In contrast, the experimental collapse was identified as $129 \mathrm{kN}$ by the snap-through point in the experimental curve. Hence the deviation in collapse load found from numerical and experimental methods is $6 \%$. Furthermore, the validated numerical methodology is extended for predicting the collapse load for varying parameters of flange angle and flange thickness and subsequently for reliability-based design optimization of the PPS.

\subsection{Design of Experiments}

The design of experiments is a systematic method to determine the factors affecting a process and the output of that process. This information is needed to manage process inputs in order to optimize the output. Response surface methodology (RSM) is used to formulate the design of experiments for developing a regression equation to predict the collapse load of PPS, which accounts for the relationship between the flange angle and flange thickness. The flange angle is limited to $30^{\circ}$ and flange thickness to $3 \mathrm{~mm}$ due to manufacturing limitations of PPS. The minimum, medium, and maximum values of the two design parameters are given in Table 4.

Table 4. Design optimization parameters

\begin{tabular}{lccc}
\hline Parameter & $\begin{array}{c}\text { Minimum } \\
(-1)\end{array}$ & $\begin{array}{c}\text { Medium } \\
(0)\end{array}$ & $\begin{array}{c}\text { Maximum } \\
(1)\end{array}$ \\
\hline Angle, $\theta[\mathrm{deg}]$ & 0 & 15 & 30 \\
\hline Thickness, $t[\mathrm{~mm}]$ & 1 & 2 & 3 \\
\hline
\end{tabular}

The load-deflection curves for all randomly generated experiments are obtained by elasto-plastic 
analysis considering Mode 23 and imperfection level of $90 \%$. Mode 23 is considered since the collapse load corresponding to the above mode is the minimum compared to the other modes under consideration. Using the twice elastic slope method, the collapse load is estimated for the design combinations as shown in Table 5.

Table 5. Generated design points and corresponding collapse load of PPS

\begin{tabular}{cccc}
\hline \multirow{2}{*}{$\begin{array}{c}\text { Angle } \\
\text { [deg] }\end{array}$} & $\begin{array}{c}\text { Thickness } \\
{[\mathrm{mm}]}\end{array}$ & \multicolumn{2}{c}{ Collapse load [N] } \\
\cline { 3 - 4 } & 0 & 42,500 & 37,220 \\
\hline 0 & -1 & 5,500 & 5,500 \\
\hline-1 & 1 & 71,250 & 67,220 \\
\hline 0 & -1 & 55,000 & 46,070 \\
\hline 1 & 1 & 120,000 & 107,500 \\
\hline 1 & -1 & 23,570 & 20,350 \\
\hline 0 & 1 & 33,880 & 34,000 \\
\hline-1 & 0 & 95,000 & 80,000 \\
\hline 1 & 0 & 42,500 & 37,220 \\
\hline 0 & 0 & 42,500 & 37,220 \\
\hline 0 & 0 & 42,500 & 37,220 \\
\hline 0 & 0 & 17,140 & 17,140 \\
\hline-1 & & &
\end{tabular}

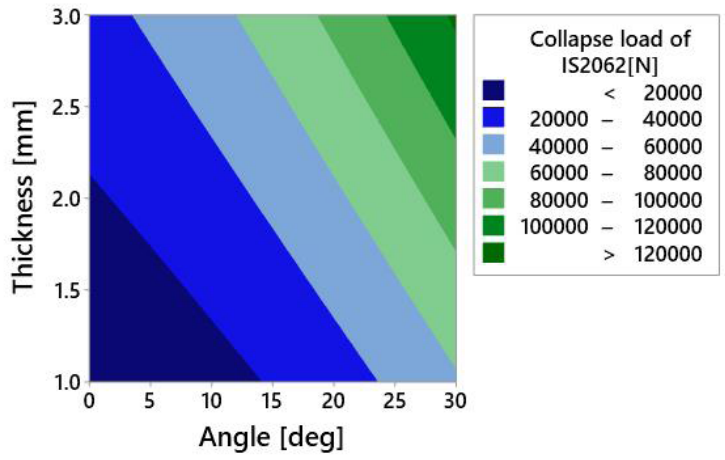

Fig. 16. Contour plot of collapse load [N] vs. thickness [mm], angle [deg] of material IS2062

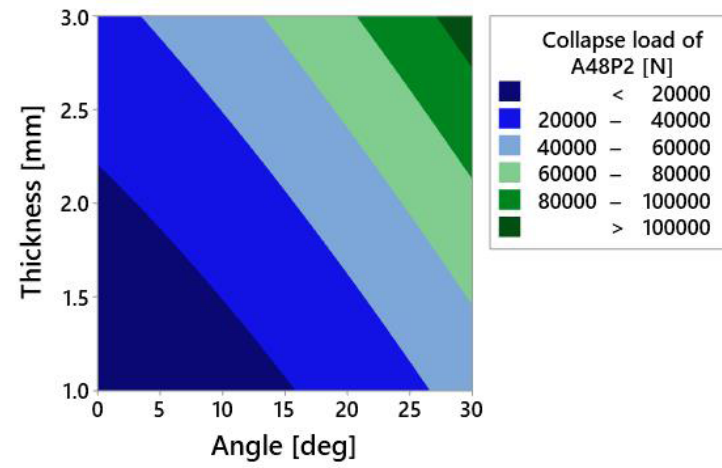

Fig. 17. Contour plot of collapse load [N] vs. thickness [mm], angle [deg] of material A48P2
It is observed that the load-carrying capacity of PPS is increasing with an increase in flange angle and flange thickness, and also follows the same pattern in the contour plot as shown in Figs. 16 and 17 for the PPS made of IS2062 and A48P2, respectively. Considering the flange angle to be constant, it is found that every $0.1 \mathrm{~mm}$ increment of flange thickness will contribute to around a $5 \%$ increase in collapse load. Similarly, keeping the thickness constant, every $1^{\circ}$ increment in flange angle will contribute to around a $4 \%$ increase in collapse load for PPS made of IS2062 and $\mathrm{A} 48 \mathrm{P} 2$.

\subsection{Reliability-Based Design Optimization of PPS}

The random variables considered for design optimization are the flange angle and flange thickness (Table 5), which follow normal distribution within a range of $15^{\circ} \pm 15^{\circ}$ and $2 \mathrm{~mm} \pm 1 \mathrm{~mm}$ respectively.

The equations for the load function obtained based on the results of collapse load for the materials IS2062 and A48P 2 are given by,

$$
\begin{aligned}
R= & 43519+(35580 \theta)+(23510 t) \\
& +\left(10005 \theta^{2}\right)+\left(1345 t^{2}\right)+(9155 \theta t), \\
R= & 38114+(30803 \theta)+(22008 t) \\
& +\left(6649 \theta^{2}\right)+\left(3434 t^{2}\right)+(9420 \theta t),
\end{aligned}
$$

where $\theta$ and $t$ are the flange angle and flange thickness, respectively. Eqs. (14) and (15) are the limit state equations for the materials IS2062 and A48P2, respectively.

$$
\begin{gathered}
g=[43519+(35580 \theta)+(23510 t) \\
\left.+\left(10005 \theta^{2}\right)+\left(1345 t^{2}\right)+(9155 \theta t)\right]-S, \\
g=[38114+(30803 \theta)+(22008 t) \\
\left.+\left(6649 \theta^{2}\right)+\left(3434 t^{2}\right)+(9420 \theta t)\right]-S, \\
\sigma_{g}{ }^{2}=\left(\frac{\partial g}{\partial \theta}\right)^{2} S_{\theta}{ }^{2}+\left(\frac{\partial g}{\partial t}\right)^{2} S_{t}^{2},
\end{gathered}
$$

where and are the standard deviations of flange angle and flange thickness of the PPS respectively. Considering Eqs. (8) to (11), (14) and (16) as input functions for reliability-based optimization with constraints $\left(\beta>3 ; 0^{\circ} \leq \theta \leq 30^{\circ} ; 1 \mathrm{~mm} \leq t \leq 3 \mathrm{~mm}\right)$, a MATLAB program is written to obtain optimum parameters of PPS that will maximize the collapse load with the minimal possible volume. Eqs. (8) to (11) account for volume, while Eqs. (14) and (16) 


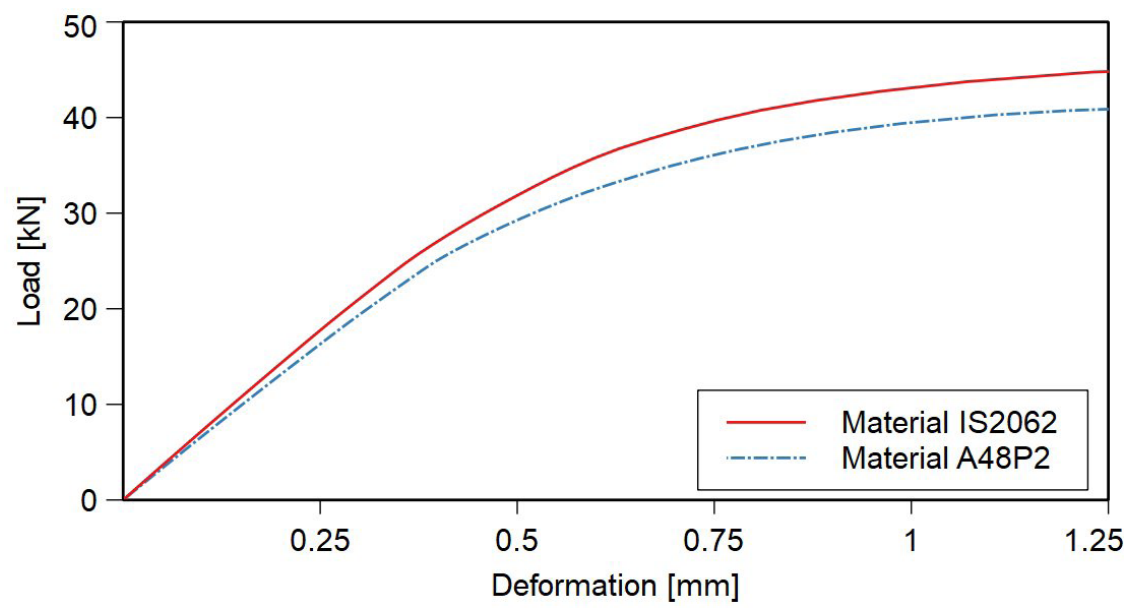

Fig. 18. Comparison of collapse load of optimized geometry of PPS

pertain to collapse load. The program is executed using a MATLAB optimization tool based on a genetic algorithm. The output of optimization is the optimum values of the flange angle and flange thickness for the PPS as given in Table 6 .

Table 6. Optimized results for PPS

\begin{tabular}{cccc}
\hline \multicolumn{2}{c}{ Material IS2062 } & \multicolumn{2}{c}{ Material A48P2 } \\
\hline Angle [deg] & Thickness [mm] & Angle [deg] & Thickness [mm] \\
\hline 19 & 1.6 & 14 & 2.1 \\
\hline
\end{tabular}

It is inferred from Fig. 18 that the collapse load of PPS is 4 and 4.5 times more than the operating load of $10 \mathrm{kN}$ considering IS2062 and A48P2, respectively. The PPS made of IS2062 has a better load-carrying capacity than that made of material A48P2. The flange angle is found to contribute significantly to the load carrying capacity of PPS. Even though the thickness of PPS made of IS2062 is comparatively lesser than that made of $\mathrm{A} 48 \mathrm{P} 2$, the collapse load is higher.

\section{CONCLUSIONS}

The reliability-based design optimization of pump penetration based on non-linear static analysis has been carried out, and the resultant optimum values are obtained for the given objective and constraints. The material non-linearity and the geometric imperfection have been taken into account. A genetic algorithmbased optimization technique is adopted for the reliability-based design of the pump penetration shell.

A study on the influence of buckling mode in predicting the collapse load reveals that the maximum deviations in collapse load are $1.3 \%$ and $7.6 \%$, respectively, for PPS made of IS2062 and A48P2.
It is inferred that the collapse load of PPS made of IS2062 is not dependent on the buckling mode shape when compared with the PPS made of A48P2. Based on the optimized results, the PPS made of IS2062 is found to have an $11 \%$ higher load-carrying capacity with $21 \%$ less material volume than the PPS made of A48P2. There is a significant improvement in the load-carrying capacity of the optimized geometry of PPS by $54 \%$ when compared to PPS with $0^{\circ}$ flange angle made of IS2062 and A48P2.

\section{ACKNOWLEDGENENTS}

The research described in this paper was financially supported by the Board of Research in Nuclear Science (BRNS), Mumbai, India (36(2)/14/39/2014BRNS/1179).

The authors are indebted to Board of Research in Nuclear Science (BRNS), Mumbai and Indra Gandhi Centre for Atomic Research (IGCAR), Kalpakkam, Tamil Nadu for their support throughout the investigation of this project work.

\section{NOMENCLATURES}

$g$ limit state function, [-]

$R$ capacity, [-]

$S$ demand, [-]

$l \quad$ length of the beam, $[\mathrm{mm}]$

$w \quad$ width of the beam, [mm]

$h$ height of the beam, [mm]

$t$ thickness of the beam, thickness of the flange, [mm]

$I_{x x}$ moment of inertia about $\mathrm{x}$-axis, $\left[\mathrm{mm}^{4}\right]$

$I_{y y}$ moment of inertia about y-axis, $\left[\mathrm{mm}^{4}\right]$ 
$P_{x} \quad$ load acting on $\mathrm{x}$-axis, $[\mathrm{N}]$

$P_{y}$ load acting on y-axis, [N]

$s_{R} \quad$ standard deviation of yield strength, [MPa]

$s_{x} \quad$ standard deviation of load acting in X-axis, [N]

$s_{y} \quad$ standard deviation of load acting in $\mathrm{y}$-axis, $[\mathrm{N}]$

$\mu$ mean, [-]

$\sigma$ standard deviation, [-]

$\beta$ reliability index, [-]

$V_{1}$ volume of hollow cylinder, $\left[\mathrm{mm}^{3}\right]$

$V_{2}$ volume of truncated hollow cone, $\left[\mathrm{mm}^{3}\right]$

$R_{1} \quad$ outer radius of hollow cylinder, [mm]

$R_{2}$ radius of hollow cylinder, [mm]

$r_{1}$ outer radius of truncated hollow cone, [mm]

$r_{2}$ radius of truncated hollow cone, [mm]

$h_{y}$ height of hollow cylinder, [mm]

$h_{c}$ height of truncated hollow cone [mm]

$\theta$ flange angle, [deg]

$S_{\theta} \quad$ standard deviation of flange angle, [deg]

$S_{t} \quad$ standard deviation of flange thickness, [mm]

\section{REFERENCES}

[1] Chellapandi, P., Puthiyavinayagam, P., Balasubramaniyan, V., Raghupathy, S., RajanBabu, V., Chetal, S.C., Baldev Raj (2011). Development of innovative reactor assembly components towards commercialization of future FBRs. Energy Procedia, vol. 7, p. 359-366, D0l:10.1016/j.egypro.2011.06.047.

[2] Prabhu Raja, V. Ramu, M., Thyla, P.R., Sriramachandra Aithal, Rajan Babu, V., Chellapandi, P. (2016). Structural design optimization of roof slab of a pool type sodium cooled fast reactor. Advances in Engineering Software, vol. 102, p. 97104, D0I:10.1016/j.advengsoft.2016.09.006.

[3] Aven, T., Jensen, U. (2013). Stochastic Models in Reliability. Springer, New York.

[4] Miura, D., Ishida, Y., Miyasaka, T., Aoki, H. Shinya, A. (2020). Reliability of different bending test methods for dental press ceramics. Materials, vol. 13, no. 22, art ID. 5162, DOI:10.3390/ma13225162.

[5] Ormon, S.W., Cassady, C.R., Greenwood, A.G. (2002). Reliability prediction models to support conceptual design. IEEE Transactions on Reliability, vol. 51, no. 2, p. 151-157, DOI:10.1109/TR.2002.1011519.

[6] Xin, T., Zhao, J., Cui, C., Duan, Y. (2020). A non-probabilistic time-variant method for structural reliability analysis. Proceedings of the Institution of Mechanical Engineers, Part 0: Journal of Risk and Reliability, vol. 234, no. 5, p. 664-675, DOI:10.1177/1748006X20928196.

[7] Zhao, X., Huang, X., Sun, J. (2020). Reliability modeling and maintenance optimization for the two-unit system with preset self-repairing mechanism. Proceedings of the Institution of
Mechanical Engineers, Part 0: Journal of Risk and Reliability, vol. 234, no. 2, p. 221-234, Dol:10.1177/1748006X19890739.

[8] Cornell, C.A. (1969). A Probability-Based Structural Code. Journal of American Concrete Institute, vol. 66, no. 12, p. 974 985.

[9] Zhou, Z., Nishida, A., Kuwamura, H. (2011). Applicability of finite element method to collapse analysis of steel connection under compression. Progress in Nuclear Science and Technology, vol. 2, p. 481-485, D0l:10.15669/pnst.2.481.

[10] Hornung, U., Saal, H. (2002). Buckling loads of tank shells with imperfections. International Journal of Non-Linear Mechanics, vol. 37, no. 4-5, p. 605-621, Dol:10.1016/S00207462(01)00087-7.

[11] Rust, W., Schweizerhof, K. (2003). Finite element limit load analysis of thin-walled structures by ANSYS (implicit), LS-DYNA (explicit) and in combination. Thin-Walled Structures, vol. 41, no. 2-3, p. 227-244, D0l:10.1016/S0263-8231(02)00089-7.

[12] Schenk, C.A., Schuëller, G.I. (2003). Buckling analysis of cylindrical shells with random geometric imperfections. International Journal of Non-Linear Mechanics, vol. 38, no. 7, p. 1119-1132, D0I:10.1016/S0020-7462(02)00057-4.

[13] Zhang, J., Zhu, B.Y., Wang, F., Tang, W.X., Wang, W.B., Zhang, M. (2017). Buckling of prolate egg-shaped domes under hydrostatic external pressure. Thin-Walled Structures, vol. 119, p. 296-303, D0I:10.1016/j.tws.2017.06.022.

[14] Wang, S., Li, Q., Savage, G.J. (2015). Reliability-based robust design optimization of structures considering uncertainty in design variables. Mathematical Problems in Engineering, vol. 2015, art ID 280940, DOl:10.1155/2015/280940.

[15] Wang, W., Wu, J.Y., Antonio, S., Lust, R. V. (1997). Deterministic design, reliability based-design and robust design. MSC Aerospace Users' Conference Proceedings, p. 1-11.

[16] Jenkins, W.M. (1991). Towards structural optimization via the genetic algorithm. Computers and Structures, vol. 40, no. 5, p. 1321-1327, DOl:10.1016/0045-7949(91)90402-8.

[17] Rani, P., Mahapatra, G.S. (2019). A neuro-particle swarm optimization logistic model fitting algorithm for software reliability analysis. Proceedings of the Institution of Mechanical Engineers, Part 0: Journal of Risk and Reliability, vol. 233, no. 6, p. 958-971, Dol:10.1177/1748006X19844784.

[18] Wang, Z., Huang, H.-Z., Liu, Y. (2010). A unified framework for integrated optimization under uncertainty. Journal of Mechanical Design. Transactions of the ASME, vol. 132, no. 5, S. 0510081-0510088, DOl:10.1115/1.4001526.

[19] Muscat, M., Mackenzie, D., Hamilton, R. (2003). A work criterion for plastic collapse. International Journal of Pressure Vessels and Piping, vol. 80, no. 1, p. 49-58, D0l:10.1016/ S0308-0161(02)00105-9.

[20] Paik, J.K., Seo, J.K. (2009). Nonlinear finite element method models for ultimate strength analysis of steel stiffenedplate structures under combined biaxial compression and lateral pressure actions - Part I: Plate elements. Thin-Walled Structures, vol. 47, no. 8-9, p. 1008-1017, D0l:10.1016/j. tws.2008.08.005. 